\title{
A Prospective study of the association between weight changes and self-rated health
}

\author{
Mette K Simonsen*1, Yrsa A Hundrup ${ }^{\dagger 2}$, Morten Grønbæk ${ }^{\dagger 3}$ and \\ Berit L Heitmann ${ }^{\dagger 1}$
}

\author{
Address: ${ }^{1}$ Research Unit for Dietary Studies, Institute of Preventive Medicine, Centre for Health and Society, Copenhagen, Denmark, ${ }^{2}$ Danish \\ Nurse Cohort Study, Research Centre for Prevention and Health (RCPH), Glostrup, Denmark and ${ }^{3}$ National Institute of Public Health, \\ Copenhagen, Denmark \\ Email: Mette K Simonsen* - mks@ipm.regionh.dk; Yrsa A Hundrup - yrsand01@glo.regionh.dk; Morten Grønbæk - mg@niph.dk; \\ Berit L Heitmann - blh@ipm.regionh.dk \\ * Corresponding author †Equal contributors
}

Published: 8 August 2008

BMC Women's Health 2008, 8:13 doi:10.1186/1472-6874-8-13

This article is available from: http://www.biomedcentral.com//472-6874/8//3

(C) 2008 Simonsen et al; licensee BioMed Central Ltd.

This is an Open Access article distributed under the terms of the Creative Commons Attribution License (http://creativecommons.org/licenses/by/2.0), which permits unrestricted use, distribution, and reproduction in any medium, provided the original work is properly cited.

\begin{abstract}
Background: Obesity and self-rated health (SRH) are strong predictors of morbidity and mortality but their interrelation is sparsely studied. The aim of this study was to analyse the association between weight changes and changes in SRH among women. We also examined if poor $\mathrm{SRH}$ at baseline was associated with later weight gain.
\end{abstract}

Methods: The Danish Nurse Cohort Study is a prospective population study (1993-1999) and comprises 13,684 female nurses aged 44 to 69 years. Logistic regression analyses were used to examine the association between weight changes and changes in $\mathrm{SRH}$.

Results: Women who gained weight during the study period had higher odds of reporting poorer self-rated health (Odds Ratio (OR): 1.18, 95\% Cl: 1.04-1.35). Weight loss among overweight women, did not result in an increase in self-rated health ratings, in fully adjusted analyses $(0.96(95 \%$ $\mathrm{Cl}$ : 0.76-I.23). Poor self-rated health combined with normal weight at first examination was associated with higher odds of later weight gain (OR: I.29, 95\% Cl: I. I0-I.5I).

Conclusion: Weight changes may result in lower SRH. Further, poor self-rated health at baseline seems to predict an increase in weight, among women without any longstanding chronic diseases. Future obesity prevention may focus on normal weight individuals with poor SRH.

\section{Background}

With more than one billion overweight adults globally, obesity has reached epidemic proportions and the World Health Organization (WHO) estimates obesity to be one of our times greatest threat to Public Health $[1,2]$. Overweight or obesity (Body Mass Index (BMI) $\geq 25 \mathrm{~kg} / \mathrm{m}^{2}$ ) increases the risk of many diseases: hypertension, type 2 diabetes, cardiovascular diseases, muscular- and skeleton diseases, and respiratory problems, among others [3]. Furthermore, obese experience social stigmatisation, rejection from the labour market, depressions $[4,5]$ and poor self-rated health [6] more often than normal weight individuals. In cross-sectional studies a J-shaped association has been found between weight and self-rated health (SRH), indicating that underweight and overweight, in particular, have negative influences on self-reported 
health ratings $[7,8]$. Thus, underlying diseases among underweight individuals may explain this J-shaped association. Studies have found several physiological advantages of weight loss among overweight individuals [9-11]. A newly published review and meta-analysis find that individuals who enter weight loss treatments emerge with less depression and greater self-esteem [12]. Similar results are found in studies examining the association between weight loss and health-related quality of life $[13,14]$. In agreement with these findings, weight gain has been shown to be associated with decreased well-being [15]. Therefore, Health Authorities usually recommend weight loss when $\mathrm{BMI} \geq 27$ [16]. Also, in the general public opinion, weight loss is associated with better healthrelated quality of life, and weight gain is associated with poor health and lower quality of life. However, prospective studies examining the association between weight changes and mortality often find contradictions to the conventional wisdom, as several of these studies find that weight loss increases mortality risk [16-18].

The purpose of this study was to examine the association between weight change and change in SRH over a 6-year period, and to analyse whether weight change had an effect on SRH. Furthermore, we wanted to examine if poor SRH at baseline was associated with later weight loss or with weight gain. SRH is a strong predictor of mortality [19], and may therefore be a useful outcome-measure, in public health prevention [20]. In the present study we hypothesized that overweight women who become normal weight, would rate their health better than women who were constantly overweight. We also wanted to analyse whether individuals who rated their health as poor at baseline, had an increased risk of later weight loss, indicating that obesity and poor SRH could be associated by reversed causality.

As a primary research question we wanted to examine if weight loss among overweight women had a negative effect on SRH (hypothesis 1). As a secondary research question we wanted to examine if poor SRH at baseline would lower the odds of gaining weight due to underlying diseases (hypothesis 2).

\section{Methods \\ Study population}

The Danish Nurse Cohort Study was established in 1993 by mailing a questionnaire to all female nurses above the age of 44 years, who were members of the Danish Nursing Council and who lived in Denmark. In all 23,170 women, of whom 19,898 (86\%) responded. The investigation was reported to the Registry Supervisory Committee (19931110-1151) and the Ethics Committee j.nr.(KF)01-103/ 93. Both committees approved the study, and the Danish Nursing Council allowed us to use the membership data- base. The cohort was re-examined in 1999. In the present study, women who received and returned a questionnaire in both 1993 and 1999 were included. In all 15,322 $(77 \%)$ responded [21]. Dropouts in 1993 and 1999, participants with no information on SRH, weight and height in 1993 and/or 1999 and participants above the age of 69 years at baseline were excluded in order to avoid age induced unintentional weight loss [22,23]. Also, the impact of weight on mortality differs between women who are younger and older than 65 years [24]. Women who were lost to follow-up were more likely to be underweight and to rate their health poorer than the responders. In total, the study population comprised 13,684 participants. Figure 1 shows the number of non-responders and dropouts due to missing information [see Figure $1]$.

\section{Variables included in the analysis \\ Exposure variables}

When we estimated the association between changes in self-reported BMI-categories and changes in SRH we used changes of BMI as exposure variable. When the exposure variable was BMI-categories, we used the WHO definition of underweight, normal weight, overweight and obesity. BMI categories, defined by the World Health Organization [1] were used to discriminate between underweight (BMI < 18.5), normal weight $(18.5 \leq \mathrm{BMI}<25.0)$, overweight $(25.0 \leq \mathrm{BMI}<30.0)$ and obese $(\mathrm{BMI} \geq 30.0)$.

\section{Outcome variables}

The outcome variable was changes in SRH from 1993 to 1999. SRH is defined as a person's assessment of own health. The women in this study were asked, "How would you rate your health in general?" and the response alternatives were: Very good, good, fair, bad, very bad. Between all five original SRH responses the change category in SRH had a total of 9 possible steps. An increase or a decrease in SRH was defined as a move, up towards better health (4 possible steps) or down towards poorer health (4 possible steps). One of the nine possible steps was no change in SRH.

\section{Potential confounders}

Age was categorized in < 49 years, 50-54 years, 55-59 years, 60-64 years, and 65-69 year intervals. Cohabitation status was dichotomised in living alone yes/no, self reported diseases: cancer, diabetes and metabolic disturbance (yes/no), use of general practitioner in past 3 months (yes/no), working: engagement in active employment (yes/no), being menopausal (yes/no), psychosocial working environment: too busy (no/yes) (Are You often so busy that it is hard to get your tasks done?) with the answering categories: never, rarely, sometimes, often, almost always. Tempo too high (yes/no) ("How do You experience the rate and pressure of the workload") with the answering 


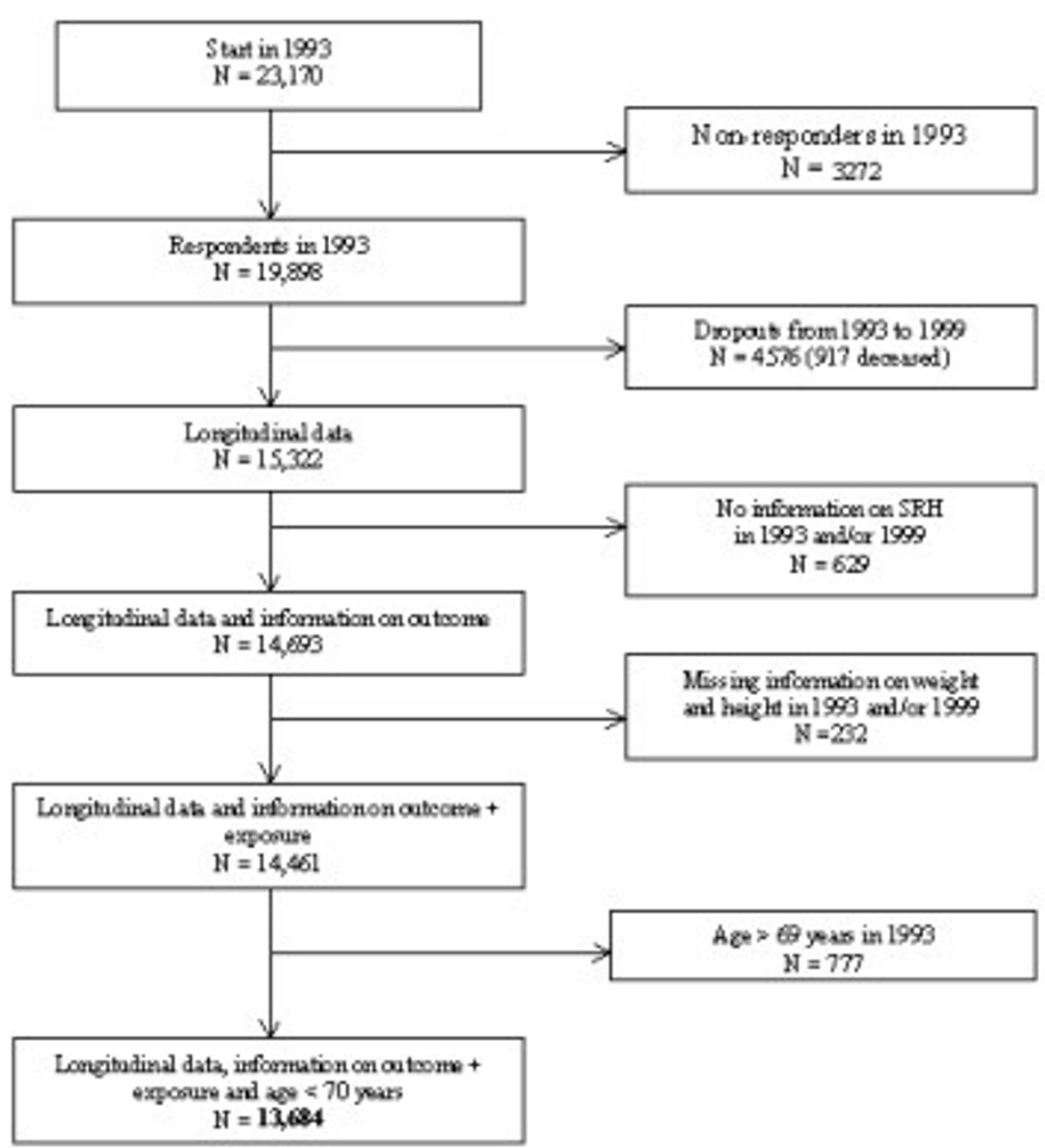

Figure I

The number of non-responders and dropouts due to missing information.

categories: far too high, a little too high, appropriate, a little to low, far too low. Influence on working day (yes/no) (" How great an influence do You normally have on the organization of Your day at work") with the answering categories: great amount of influence, some amount of influence, a little amount of influence and no influence. Daily smoking (yes/no), Diet: daily consumption of fruit and vegetables (yes/no), physical activity more than 4 hours/week (yes/no), alcohol consumption $>5$ units last weekend (yes/no).

\section{Statistical analysis}

Data were analysed by means of multivariate logistic regression analysis with odds ratio (OR) and 95\% confidence intervals. All important potential confounding factors with $\mathrm{p}$-values $<0.25$ in the univariate analyses were included in the multivariate analyses. In the multivariate analysis we made the analyses with all potential confounders and then excluded insignificant variables to reduce loss of individuals. Interaction between BMIchanges and selected variables (age, cohabitation status, smoking status and psychosocial working environment factors at baseline) were statistically tested by means of logistic regression analysis.

When examining our secondary hypothesis we wanted to examine the odds of gaining weight among women who rated their health as sub-optimal (fair, poor or very poor) at baseline. An increase or a decrease in SRH was still defined as a move, up towards better health (4 possible steps) or down towards poorer health (4 possible steps). Statistical analyses were performed using SAS version 9.1.

\section{Results}

At entry, the mean age was 53.8 years (range 45 to 69 years, SD 6.47) and the mean height was $166 \mathrm{~cm}$ (range $130 \mathrm{~cm}$ to $191 \mathrm{~cm}, \mathrm{SD} 5.63)$. Mean BMI increased from $23.6 \mathrm{~kg} / \mathrm{m}^{2}$ (range $13-65 \mathrm{~kg} / \mathrm{m}^{2}$ ) in 1993 to BMI $24.4 \mathrm{~kg} /$ $\mathrm{m}^{2}$ in 1999. During the study period, 7898 (57.7\%) women maintained a normal weight, 2313 (16.9\%) gained weight and 601 women (4.4\%) lost weight according to the WHO BMI-categories. Almost $80 \%(n=10,770)$ 
of the women stayed in the same BMI-category both years and $20 \%$ changed BMI-category during the study period. At baseline, 11,596 (85\%) rated their health as very good or good. Fifty-nine percent experienced no change in SRH. Twenty-three percent of the women rated their health poorer and $18 \%$ rated their health better according to the nine steps scale of SRH.

\section{Description of the study population}

The percentage distribution of women who rated their health better (increase) or worse (decrease) in the period 1993 to 1999 is showed in Table 1 [see Table 1]. More than half of the women (59\%) experienced no change in SRH and more rated their health poorer than better during the study period. Twenty three percent experienced a decrease in SRH and 18\% experienced an increase in SRH [see Table 1].

Table 2 shows baseline characteristics of the participants according to BMI categories in 1993 and in 1999 [see Table 2]. Individuals who were underweight in 1993 and who rated their health poorer during the study period were more likely to stay underweight in 1999 (61\%).

Ninety percent of the women who were normal weight in 1993, but overweight in 1993, rated their health poorer. Of the women who were underweight in 1993 and 1999, about half were smoking (51\%). Among individuals who gained from normal weight to overweight, $22 \%$ compared to $76 \%$ of the women with stable normal weight, were not physically active [see Table 2]. Table 3 shows baseline characteristics (\%) in relation to baseline SRH [see Table $3]$. When we compare the women who rated their health as very good in 1993 with the women who rated their health very poor, we find that the women with poor SRH smoke more and exercise less.

\section{Association between SRH and weight changes}

When women gained from underweight to normal weight, the odds showed a decrease in SRH (OR: 0. 59, 95\% CI:0. 35-0.99) [see Table 4]. The odds of a decrease in SRH were higher among women who gained weight from normal weight to overweight OR: 1.18, 95\%CI: 1.04-1.35). To lose weight from overweight in 1993 to normal weight in 1999 did not have an effect on health ratings (OR: 0.96, 95\% CI: 0.76-1.23). The association between sub-optimal SRH at baseline (1993) and the odds of later weight gain (OR: $1.29,95 \% \mathrm{CI}: 1.10-1.51$ ) is shown in Table 5 [see Table 5].

\section{Discussion}

As a primary research question we hypothesised that weight changes were associated with changes in SRH (hypothesis 1). However, we anticipated that overweight women, who lost weight and became normal weight, would rate their health better than women who were overweight in both 1993 and 1999. We found that women who had been overweight and became normal weight, did

Table I: Percentage distribution of changes in self-rated (SHR) by nine possible steps $(n=13,684)$

\begin{tabular}{|c|c|c|c|}
\hline $\begin{array}{l}\text { Number of steps of change in SRH in the period from } \\
\qquad 1993 \text { to } 1999\end{array}$ & Changes in SRH from 1993 to 1999 & $\mathbf{N}$ & Percent (\%) \\
\hline-4 & From very good SRH in 1993 to very poor SRH in 1999 & 2 & 0.01 \\
\hline \multirow[t]{2}{*}{-3} & From very good SRH in 1993 to poorly SRH in 1999 & 36 & 0.3 \\
\hline & From good SRH in 1993 to very poor SRH in 1999 & & \\
\hline \multirow[t]{3}{*}{-2} & From very good SRH in 1993 to fair SRH in 1999 & 317 & 2.3 \\
\hline & From good SRH in 1993 to poor SRH in 1999 & & \\
\hline & From fair SRH in 1993 to very poor SRH in 1999 & & \\
\hline \multirow[t]{4}{*}{-1} & From very good SRH in 1993 to good SRH in 1999 & 2790 & 20.3 \\
\hline & From good SRH in 1993 to fair SRH in 1999 & & \\
\hline & From fair SRH in 1993 to poor SRH in 1999 & & \\
\hline & From poor SRH in 1993 to very poor SRH in 1999 & & \\
\hline 0 & No change in SRH & 8102 & 59.2 \\
\hline \multirow[t]{4}{*}{1} & From good SRH in 1993 to good very SRH in 1999 & 2266 & 16.5 \\
\hline & From fair SRH in 1993 to very poor SRH in 1999 & & \\
\hline & From poor SRH in 1993 to fair SRH in 1999 & & \\
\hline & From very poor SRH in 1993 to poor SRH in 1999 & & \\
\hline \multirow[t]{3}{*}{2} & From fair SRH in 1993 to very good SRH in 1999 & 155 & I.I \\
\hline & From poor SRH in 1993 to good SRH in 1999 & & \\
\hline & From very poor SRH in 1993 to fair SRH in 1999 & & \\
\hline \multirow[t]{2}{*}{3} & From poor SRH in 1993 to very good SRH in 1999 & 15 & 0.1 \\
\hline & From very poor SRH in 1993 to good SRH in 1999 & & \\
\hline 4 & From very poor SRH in 1993 to very good SRH in 1999 & I & 0.01 \\
\hline Total & & 13684 & 100.00 \\
\hline
\end{tabular}


Table 2: Baseline characteristics (\%) in relation to changes in BMI $\left(\mathrm{kg} / \mathrm{m}^{2}\right)(\mathrm{n}=13,684)$

\begin{tabular}{|c|c|c|c|c|c|c|c|c|c|c|c|c|}
\hline \multirow{2}{*}{$\begin{array}{c}\text { Baseline } \\
\text { characteristi } \\
\text { cs (1993) }\end{array}$} & \multicolumn{4}{|c|}{$\begin{array}{l}\text { Underweight women in } 1993 \\
\quad(\mathrm{BMI}<18.5) \mathrm{n}=309\end{array}$} & \multicolumn{4}{|c|}{$\begin{array}{l}\text { Normal weight women in } 1993 \\
(18.5 \leq \mathrm{BMI}<25.0) \mathrm{n}=9676\end{array}$} & \multicolumn{4}{|c|}{$\begin{array}{l}\text { Overweight women in I993 (BMI } \geq 25) \\
\qquad n=3699\end{array}$} \\
\hline & $\begin{array}{c}\text { Under- } \\
\text { weight } \\
1999\end{array}$ & $\begin{array}{c}\text { Normal } \\
\text { weight } \\
1999\end{array}$ & $\begin{array}{l}\text { Overwei } \\
\text { ght } 1999\end{array}$ & $n$ & $\begin{array}{l}\text { Under- } \\
\text { weight } \\
1999\end{array}$ & $\begin{array}{c}\text { Normal } \\
\text { weight } \\
1999\end{array}$ & $\begin{array}{l}\text { Overwei } \\
\text { ght } 1999\end{array}$ & $n$ & $\begin{array}{l}\text { Under- } \\
\text { weight } \\
1999\end{array}$ & $\begin{array}{c}\text { Normal } \\
\text { weight } \\
1999\end{array}$ & $\begin{array}{l}\text { Overwei } \\
\text { ght } 1999\end{array}$ & $n$ \\
\hline \multicolumn{13}{|l|}{ Age } \\
\hline-49 & 38 & 62 & 0 & 106 & I & 79 & 20 & 3428 & 0 & 7 & 93 & 1013 \\
\hline $50-54$ & 49 & 51 & 0 & 67 & I & 82 & 17 & 2293 & 0 & 10 & 90 & 868 \\
\hline $55-59$ & 57 & 43 & 0 & 77 & I & 84 & 15 & 2039 & 1 & 9 & 90 & 907 \\
\hline $60-64$ & 64 & 36 & 0 & 36 & 2 & 81 & 17 & 1249 & 1 & 13 & 86 & 595 \\
\hline 65-69 & 78 & 22 & 0 & 23 & I & 86 & 13 & 667 & 1 & 13 & 86 & 316 \\
\hline \multicolumn{13}{|l|}{$\begin{array}{r}\text { Cohabitati } \\
\text { on }\end{array}$} \\
\hline Yes & 49 & 51 & 0 & 214 & I & 82 & 17 & 7449 & 1 & 10 & 90 & 2813 \\
\hline No & 56 & 44 & 0 & 75 & I & 80 & 19 & 1886 & 1 & 11 & 88 & 750 \\
\hline \multicolumn{13}{|l|}{ Working } \\
\hline Yes & 46 & 54 & 0 & 226 & I & 82 & 17 & 7475 & 1 & 9 & 90 & 2695 \\
\hline No & 69 & 31 & 0 & 74 & 2 & 82 & 16 & 1901 & $\mathrm{I}$ & 12 & 87 & 907 \\
\hline \multicolumn{13}{|l|}{ Smoking } \\
\hline No & 49 & 51 & 0 & 109 & 1 & 82 & 17 & 5715 & 1 & 9 & 90 & 2478 \\
\hline Yes & 52 & 48 & 0 & 184 & 2 & 81 & 16 & 3522 & 1 & 12 & 87 & 1028 \\
\hline \multicolumn{13}{|l|}{$\begin{array}{l}\text { Physical } \\
\text { activity }\end{array}$} \\
\hline Yes & 52 & 48 & 0 & 278 & I & 82 & 17 & 9180 & 1 & 10 & 89 & 3389 \\
\hline No & 46 & 54 & 0 & 28 & 2 & 76 & 22 & 410 & 0 & 10 & 91 & 267 \\
\hline
\end{tabular}

not rate their health better than before and the women experienced a decrease in SRH, when they gained from normal weight in 1993 to overweight in 1999.

Only women, who were underweight at baseline and had become normal weight in 1999, experienced an increase in SRH during the study period. This group may consist of women getting well after being affected by illness.

As a secondary research question we wanted to examine if poor SRH at baseline lowered the odds of gaining weight due to underlying diseases (hypothesis 2). However, contrary to what we initially expected, we found that poor health at baseline increased the odds of later weight gain. Kristensen et al [6] have suggested this relation to be caused by a more unhealthy lifestyle among people who rate their health as poor. Manderbacka et al [25] found similar results when they investigated the association between lifestyle and $\mathrm{SRH}$, with data from a face-to-face survey, among a sample representative of the Swedish population. One of the conclusions in that study was that poor life-style was associated with poor health. The results from the current study point toward the conclusion that weight stability is more beneficial to health ratings than any weight change. Also, a suboptimal SRH may be a predictor of later weight gain.

Several cross-sectional studies have found an association between obesity and SRH, and other related health measures, such as life satisfaction $[8,26,27]$. These studies find an association between obesity and poor SRH, or life satisfaction, and suggest that obesity may lead to poor SRH. However, none of the studies have examined the reversed causality. One study only examined the association between weight change and change in health-related life satisfaction [14]. They found that compared to remaining overweight, weight loss among the obese was associated with gain in health-related quality of life (HRQL) [14]. However, health-related quality of life and SRH may be two different measures, and our results may therefore not be comparable [28].

There is general agreement that SRH provides a useful summary of how individuals perceive their overall health status, including both physical and mental health. A large number of studies have consistently shown, in a wide range of disease areas, that SRH is a powerful predictor of clinical outcome and mortality [29-31]. A meta-analysis of 117 weight loss treatment tests showed that people 
Table 3: Baseline characteristics $(\%)$ in relation to baseline self-rated health $(n=13,684)$

\begin{tabular}{|c|c|c|c|c|c|c|c|c|c|c|c|}
\hline \multirow{2}{*}{$\begin{array}{c}\text { Baseline } \\
\text { characteristics } \\
(1993)\end{array}$} & \multicolumn{11}{|c|}{ Self-Rated Health at base-line $(N=13684)$} \\
\hline & $\begin{array}{l}\text { Very good SRH } \\
\quad(\mathrm{n}=5450)\end{array}$ & $n$ & $\begin{array}{l}\text { Good SRH } \\
(n=6146)\end{array}$ & $n$ & $\begin{array}{l}\text { Fair SRH } \\
(\mathrm{n}=1833)\end{array}$ & $n$ & $\begin{array}{l}\text { Poor SRH } \\
(n=222)\end{array}$ & $n$ & $\begin{array}{l}\text { Very poor SRH } \\
\quad(n=33)\end{array}$ & $n$ & \\
\hline \multicolumn{12}{|l|}{ Age } \\
\hline-49 & 40 & 2160 & 32 & 1941 & 21 & 388 & 22 & 48 & 30 & 10 & 4547 \\
\hline $50-54$ & 24 & 1299 & 24 & 1456 & 22 & 410 & 25 & 56 & 21 & 7 & 3228 \\
\hline $55-59$ & 19 & 1032 & 23 & 1385 & 29 & 520 & 35 & 77 & 27 & 9 & 3023 \\
\hline $60-64$ & 12 & 653 & 14 & 883 & 17 & 319 & 9 & 20 & 15 & 5 & 1880 \\
\hline 65-69 & 6 & 306 & 8 & 481 & 11 & 196 & 9 & 21 & 6 & 2 & 1006 \\
\hline \multicolumn{12}{|l|}{$\begin{array}{r}\text { Self-rated } \\
\text { health }\end{array}$} \\
\hline Better (increase) & 0 & 0 & 25 & 1507 & 41 & 751 & 69 & 153 & 79 & 26 & 2437 \\
\hline Unchanged & 65 & 3543 & 58 & 3556 & 51 & 931 & 30 & 65 & 21 & 7 & 8102 \\
\hline $\begin{array}{r}\text { Poorer } \\
\text { (decrease) }\end{array}$ & 35 & 1907 & 18 & 1083 & 8 & 151 & 2 & 4 & 0 & 0 & 3145 \\
\hline \multicolumn{12}{|l|}{ Cohabitation } \\
\hline Yes & 82 & 4285 & 79 & 4701 & 75 & 1316 & 68 & 148 & 81 & 26 & 10476 \\
\hline No & 18 & 972 & 21 & 1223 & 26 & 440 & 32 & 70 & 19 & 6 & $27 I I$ \\
\hline \multicolumn{12}{|l|}{ Working } \\
\hline Yes & 86 & 4497 & 79 & 4720 & 60 & 1067 & 46 & 100 & 38 & 12 & 10396 \\
\hline No & 14 & 789 & 21 & 1231 & 40 & 722 & 54 & 120 & 62 & 20 & 2882 \\
\hline \multicolumn{12}{|l|}{ Smoking } \\
\hline No & 66 & 3436 & 64 & 3737 & 57 & 997 & 56 & 118 & 44 & 14 & 8302 \\
\hline Yes & 34 & 1761 & 36 & 2121 & 43 & 742 & 44 & 92 & 56 & 18 & 4734 \\
\hline \multicolumn{12}{|l|}{$\begin{array}{l}\text { Physical } \\
\text { activity }\end{array}$} \\
\hline Yes & 97 & 5230 & 95 & $58 / 8$ & 90 & 1617 & 77 & 164 & 66 & 21 & 12847 \\
\hline No & 3 & 187 & 5 & 277 & 10 & 180 & 23 & 50 & 34 & 11 & 705 \\
\hline
\end{tabular}

who enter weight loss treatments (intentional) seem to emerge with less depression and greater self-esteem [12]. However, health-related quality of life and self-esteem are different concepts a different meaning to people, than the concept of SRH. We have found no other published results that were comparable to ours, e.g. that studied the association between weight changes and changes in SRH.

\section{Strengths and weaknesses}

The present study is based on a large population of Danish female nurses $(n=19,898)$ with a high response rate at baseline (86\%) and at follow-up (77\%). The Danish
Nurse Cohort Study consists of a homogeneous group in relation to several potential confounding factors. The nurses have the same sex, same education and only a small spread in age (44-69 years). Danish nurses exercise more, smoke less, are slimmer and rate their health better, than the general female population in Denmark [32], which may have resulted in an underestimation of the true associations. Potential confounding factors, exposure and outcome measures, are based on self-reported data, which raise a question regarding validity. It is well known that overweight women have a tendency to underreport their weight $[33,34]$. An American study estimated that

Table 4: Odds Ratio (OR) and $95 \% \mathrm{Cl}$ for a decrease in SRH by weight changes $(n=13,684)$

\begin{tabular}{|c|c|c|c|}
\hline Changes in BMI categories from 1993 to 1999 & $\begin{array}{l}\text { Underweight in } 1999 \\
\left(\mathrm{BMI}<18.5 \mathrm{~kg} / \mathrm{m}^{2}\right)\end{array}$ & $\begin{array}{c}\text { Normal weight in } 1999 \\
\left(18.5 \mathrm{~kg} / \mathrm{m}^{2} \leq \mathrm{BMI}<25.0 \mathrm{~kg} / \mathrm{m}^{2}\right)\end{array}$ & $\begin{array}{l}\text { Overweight in } 1999 \\
\left(\mathrm{BMI} \geq 25 \mathrm{~kg} / \mathrm{m}^{2}\right)\end{array}$ \\
\hline Underweight in $1993\left(\mathrm{BMI}<18.5 \mathrm{~kg} / \mathrm{m}^{2}\right)$ & 1.0 (reference) & $0.59(0.35-0.99)$ & --- \\
\hline Normal weight in $1993\left(18.5 \leq \mathrm{BMI}<25.0 \mathrm{~kg} / \mathrm{m}^{2}\right)$ & $1.46(0.93-2.29)$ & 1.0 (reference) & $1.18(1.04-1.35)$ \\
\hline Overweight in $1993\left(\mathrm{BMI} \geq 25 \mathrm{~kg} / \mathrm{m}^{2}\right)$ & --. & $0.96(0.76-1.23)$ & 1.0 (reference) \\
\hline
\end{tabular}

* Adjusted for age, cohabitation status, diabetes, metabolic disturbance, use of General Practitioner last 3 months, engaged in active employment, menopause, smoking, diet (consumption of vegetables). 
Table 5: Odds Ratio (OR) and $95 \% \mathrm{Cl}$ for weight gain by sub-optimal SRH at baseline $(\mathrm{n}=9,0 \mathrm{I} 2)$.

\begin{tabular}{|c|c|c|}
\hline & $\begin{array}{c}\text { Odds Ratio (OR) and } 95 \% \mathrm{Cl} \text { for weight gain according to sub-optimal self- } \\
\text { rated health at baseline }\end{array}$ & P-value \\
\hline Self-rated health in 1993 & & $<0,0019$ \\
\hline Optimal (very good or good) & I (reference) & \\
\hline Sub-optimal (fair, poor or very poor) & $1,29(1, \mid 0-1,51)$ & \\
\hline Age & & $<0,0001$ \\
\hline - 49 years & I (reference) & \\
\hline $50-54$ years & $0,84(0,73-0,97)$ & $0,014 \mid$ \\
\hline $55-59$ years & $0,67(0,57-0,78)$ & $<0,0001$ \\
\hline $60-64$ years & $0,80(0,66-0,95)$ & 0,0119 \\
\hline $65-69$ years & $0,57(0,44-0,73)$ & $<0,0001$ \\
\hline Living arrangement & & 0,0005 \\
\hline Cohabiting & I (reference) & \\
\hline Living alone & $1,27(1,11-1,45)$ & \\
\hline Use of general practitioner past 3 months & & 0,0002 \\
\hline Less & I (reference) & \\
\hline More & $0,8 \mid(0,72-0,90)$ & \\
\hline
\end{tabular}

Women who lost weight were excluded from the analysis.

* Adjusted for age, living arrangements, diabetes, metabolic disturbance, use of General Practitioner last 3 months, engaged in active employment, menopause, psycho-social working environment (busyness), smoking, diet (consuming vegetables)

$35 \%$ of all adult women underreported their weights [35]. Indeed, if the obese women systematically misinformed about their weight, a specific misclassification bias may have been a problem in the present study and if the nurses tended to underreport weight in 1999 compared to 1993, the effect on SRH will have been underestimated. Validation on weight measures in the Danish Nurse Cohort Study is still lacking. When discussing the association between weight changes and SRH, the intention behind the weight changes is an important issue. In some cases it may be assumed that unintentional weight loss would have a negative impact of SRH, as unintentional weight changes may be caused by diseases or life style changes such as lack of physical activity or change in diet. However, weight gain can also be a sign of regained health or of increased unhealthy behaviour. Also, weight loss can be caused by several reasons such as successful slimming efforts or change of life style or diseases. Studies have shown associations between depressed mood and weight gain [36]. When measuring changes in SRH the statistical problem "Regression towards mean" may occur and will increase the likelihood that women who rated their health very poor in 1993 would rate it less poor in 1999. In our study less than $2 \%(n=255)$ of the women rated their health poor and very poor at baseline.

Furthermore, a "floor and ceiling effect" may have occurred in this study reducing the variation and the potential for finding associations even if present. This problem may have attenuated the results in this study. Unfortunately, useful information on intentional weight loss was not accessible. We controlled for several important diseases including use of general practitioner, and still found significant association. However, the risk of residual confounding by underlying diseases may still be a possibility.

\section{Conclusion}

In a summery, we found an association between changes in BMI and changes in SRH. Women who were underweight in 1993 but normal weight in 1999, rated their health better than the women who were underweight throughout the study period. Women who were normal weight in 1993 but overweight in 1999 rated their health poorer than women who were normal weight both years. Surprisingly, women who were overweight in 1993 but normal weight in 1999, did not rate their health better than those who remained overweight. This could be due to diseases not controlled for or due to unintentional weight loss among the overweight and obese. There is a need for further research of the health consequences concerning weight changes. Health benefits or consequences of a stable overweight compared to a weight loss among overweight women are still unknown. It would be most essential for public health to examine this issue further as the obesity problem grows and more people than ever are trying to lose weight. More studies examining relations of intentional changes in body weight and health consequences are warranted.

\section{Competing interests}

The authors declare that they have no competing interests.

\section{Authors' contributions}

MKS carried out the analysis and drafted the manuscript. YAH and MG participated in the design of the study and 
data. BLH participated in the design of the study and assisted with the draft of the manuscript and the statistical analysis. All authors read and approved the final manuscript.

\section{Acknowledgements}

We thank the steering group of the Danish Nurse Cohort Study who lent us the data.

\section{References}

I. Organization WH: Obesity: Preventing and managing the Global Epidemic. June 3-5 1997 Geneva; 1998.

2. Ministry of the Interior and Health: Health throughout life - Targets and strategies for public health policy og the Government of Denmark 200220102002.

3. B A: Obesity, Life Style and Society. Psychological and psychosocial factors in relation to body weight and body weight changes. Stockholm, The Department of Medicine, Karolinska Instituttet; 2004.

4. Rossner S: Obesity: the disease of the twenty-first century. Int J Obes Relat Metab Disord 2002, 26 Suppl 4:S2-S4.

5. Kimm SY, Barton BA, Berhane K, Ross JW, Payne GH, Schreiber GB: Self-esteem and adiposity in black and white girls: the NHLBI Growth and Health Study. Ann Epidemiol 1997, 7:550-560.

6. Kristensen TS, Bjorner J, Smith-Hansen L, Borg V, Skov T: Self-rated health and working environment - Is self-rated health a productive and useful concept for working environment research and prevention Arbejdsmiljøfondet; 1998.

7. Okosun IS, Choi S, Matamoros T, Dever GE: Obesity is associated with reduced self-rated general health status: evidence from a representative sample of white, black, and Hispanic Americans. Prev Med 200I, 32:429-436.

8. Ferraro KF, Yu Y: Body weight and self-ratings of health. J Health Soc Behav 1995, 36:274-284.

9. Williamson DF: Weight loss and mortality in persons with type-2 diabetes mellitus: a review of the epidemiological evidence. Exp Clin Endocrinol Diabetes 1998, 106 Suppl 2:14-21.

10. Eilat-Adar S, Eldar M, Goldbourt U: Association of intentional changes in body weight with coronary heart disease event rates in overweight subjects who have an additional coronary risk factor. Am J Epidemiol 2005, 161:352-358.

II. Heitmann BL, Svendsen OL, Martinussen T, Mikkelsen KL, Keiding N, Sorensen TI, Astrup AV: [Significance of intentional weight loss on health]. Ugeskr Laeger 1997, I59:4099-4I04.

12. Blaine BE, Rodman J, Newman JM: Weight loss treatment and psychological well-being: a review and meta-analysis. J Health Psychol 2007, I 2:66-82.

13. Blissmer B, Riebe D, Dye G, Ruggiero L, Greene G, Caldwell M: Health-related quality of life following a clinical weight loss intervention among overweight and obese adults: intervention and 24 month follow-up effects. Health Qual Life Outcomes 2006, 4:43.

14. Fine JT, Colditz GA, Coakley EH, Moseley G, Manson JE, Willett WC, Kawachi I: A prospective study of weight change and healthrelated quality of life in women. JAMA 1999, 282:2। 36-2|42.

15. Williams LT, Young AF, Brown WJ: Weight gained in two years by a population of mid-aged women: how much is too much? Int J Obes (Lond) 2006, 30:1229-1233.

16. Sorensen TI, Rissanen A, Korkeila M, Kaprio J: Intention to lose weight, weight changes, and 18-y mortality in overweight individuals without co-morbidities. PLoS Med 2005, 2:e I7I.

17. Yaari S, Goldbourt U: Voluntary and involuntary weight loss: associations with long term mortality in 9,228 middle-aged and elderly men. Am J Epidemiol 1998, I 48:546-555.

18. Nilsson PM, Nilsson JA, Hedblad B, Berglund G, Lindgarde F: The enigma of increased non-cancer mortality after weight loss in healthy men who are overweight or obese. J Intern Med 2002, 252:70-78.

19. Idler EL, Benyamini Y: Self-rated health and mortality: a review of twenty-seven community studies. J Health Soc Behav 1997, 38:2I-37.
20. Iversen L, Johansen $\mathrm{D}$, Gronbaek $\mathrm{MN}$ : [The relation between life style, socioeconomic factors, social networks and suboptimal self-assessed health]. Ugeskr Laeger 2002, I64:I497-I50I.

21. Hundrup YA, Obel EB, Rasmussen NK, Gronbaek M: [The Danish Nurse Cohort Study 1993-2003]. Ugeskr Laeger 2004, 166: | $45 \mid-1454$

22. Lee JS, Kritchevsky SB, Tylavsky F, Harris T, Simonsick EM, Rubin SM, Newman $A B$ : Weight change, weight change intention, and the incidence of mobility limitation in well-functioning community-dwelling older adults. J Gerontol A Biol Sci Med Sci 2005, 60:1007-1012.

23. Newmann AB, Yanez D, Harris T, Duxbury, A, Enright PL, Fried L: Weight Change in Old Age and its Association with Mortality Volume 49. 10th edition. The Journal of the American Geriatrics Society; 200I:1309-1318.

24. Stevens J, Cai J, Pamuk ER, Williamson DF, Thun MJ, Wood JL: The effect of age on the association between body-mass index and mortality. N Engl J Med I998, 338: I-7.

25. Manderbacka K, Lundberg O, Martikainen P: Do risk factors and health behaviours contribute to self-ratings of health? Soc Sci Med 1999, 48: 1713-1720.

26. Ford ES, Moriarty DG, Zack MM, Mokdad AH, Chapman DP: Selfreported body mass index and health-related quality of life: findings from the Behavioral Risk Factor Surveillance System. Obes Res 200I, 9:2I-3I.

27. Larsson U, Karlsson J, Sullivan M: Impact of overweight and obesity on health-related quality of life--a Swedish population study. Int J Obes Relat Metab Disord 2002, 26:4I7-424.

28. Bradley C: Importance of differentiating health status from quality of life. Lancet 200I, 357:7-8.

29. Singh-Manoux A, Martikainen P, Ferrie J, Zins M, Marmot M, Goldberg $M$ : What does self rated health measure? Results from the British Whitehall II and French Gazel cohort studies. J Epidemiol Community Health 2006, 60:364-372.

30. Alonso J, Ferrer M, Gandek B, Ware JE Jr., Aaronson NK, Mosconi P, Rasmussen NK, Bullinger M, Fukuhara S, Kaasa S, Leplege A: Healthrelated quality of life associated with chronic conditions in eight countries: results from the International Quality of Life Assessment (IQOLA) Project. Qual Life Res 2004, 13:283-298.

31. Fayers PM, Sprangers MA: Understanding self-rated health 8. Lancet 2002, 359:187-188.

32. Friis K, Ekholm O, Hundrup YA: Comparison of lifestyle and health among Danish nurses and the Danish female population: is it possible to generalize findings from nurses to the general female population? Scand J Caring Sci 2005, 19:36I-367.

33. Lissner L, Habicht JP, Strupp BJ, Levitsky DA, Haas JD, Roe DA: Body composition and energy intake: do overweight women overeat and underreport? Am / Clin Nutr 1989, 49:320-325.

34. Perry GS, Byers TE, Mokdad AH, Serdula MK, Williamson DF: The validity of self-reports of past body weights by U.S. adults. Epidemiology 1995, 6:61-66.

35. Villanueva EV: The validity of self-reported weight in US adults: a population based cross-sectional study. BMC Public Health 200I, I:II.

36. Sammel MD, Grisso JA, Freeman EW, Hollander L, Liu L, Liu S, Nelson DB, Battistini M: Weight gain among women in the late reproductive years. Fam Pract 2003, 20:40I-409.

\section{Pre-publication history}

The pre-publication history for this paper can be accessed here:

http://www.biomedcentral.com/1472-6874/8/13/prepub 